\title{
Comparison of Native and Regenerated Antheraea Pernyi Silk Fibroin
}

\author{
Yu DUAN, Xin CHEN, Zhengzhong SHAO*
}

\author{
State Key Laboratory of Molecular Engineering of Polymers, Department of Macromolecular Science, Laboratory of \\ Advanced Materials, Fudan University, Shanghai 200438, China
}

crossref http://dx.doi.org/10.5755/j02.ms.22784

Received 17 February 2019; accepted 02 May 2019

\begin{abstract}
The regenerated Antheraea pernyi silk fibroin (RASF) was harvested by dissolving the silk fibers in a calcium nitrate solution. XRD result demonstrated that both native and regenerated Antheraea pernyi silk fibroin involved the $\alpha$-helix conformation, and DTG curves showed that their thermal decompositions were quite similar and proceeded three steps. However, rheological measurements figured out that the molecule weight of RASF decreased from $246 \mathrm{kDa}$ to $199 \mathrm{kDa}$, comparing with native Antheraea pernyi silk fibroin. Also, the tensile properties of the RASF film, which were the same to those of regenerated Bombyx mori silk fibroin film, were observed.

Keywords: Antheraea Pernyi silk, silk fibroin, molecular weight, mechanical property.
\end{abstract}

\section{INTRODUCTION}

Silk fibroin (SF) is a kind of natural protein derived from different silkworms, either domestic (Bombyx mori) or wild (Antheraea pernyi, Antheraea assama, Samia cynthia ricini, etc) ones [1-3]. Because of its tunable morphology and wonderful biocompatibility, SF has attracted scientists' attention for many decades [4 -6]. The regenerated Bombyx mori silk fibroin (RBSF) has been widely investigated and produced to bio-related materials with various shape and properties, including microspheres, electrospun fibers, films, hydrogels, scaffolds, etc [7 - 10]. Otherwise the materials based on regenerated Antheraea pernyi silk fibroin (RASF) were limited by lack of regenerated solution.

Unlike the Bombyx mori (B. mori) silk, the Antheraea pernyi (A. pernyi) silk is very difficult to be dissolved because of the differences not only on the amino acid compositions and sequences of these two silk proteins (fibroins) but also on the organization of the silk fibers. Generally, the A. pernyi silk fibroin (ASF) contains poly(Ala) segments while the $B$. mori silk fibroin (BSF) is dominated by the sequence of GAGAGAGS [11-13]. Additionally, ASF has the characteristic tripeptide sequence Arg-Gly-Asp (RGD), which is recognized to have special interaction with extracellular matrix of mammalian cells [14]. The presence of RGD sequences in ASF is advantageous over domestic silk fibroin, which provides us an opportunity to prepare biomedical materials with better bio-properties than those derived from $B$. mori silk fibroin $[15,16]$. Based on this feature, the interests rise in the use of ASF as raw material for advanced biomedical applications. However, the early researchers usually collected ASF solution from the full-grown silkworms' silk gland [17-19]. Such extraction process is complicated and the amount of the material may be not enough to meet the requirement of research and application.

\footnotetext{
* Corresponding author. Tel.: +86-21-31249907.

E-mail address: zzshao@fudan.edu.cn (Z. Shao)
}

Therefore, it is necessary to dissolve A. pernyi silk fibers to regenerate A. pernyi silk fibroin. Recently, researchers used lithium thiocyanate solution or $\mathrm{Ca}\left(\mathrm{NO}_{3}\right)_{2}$ to produce RASF aqueous solution $[16,20,21]$. There is a direct correlation between properties of solution and characteristics of material [22, 23]. Comprehensive studies of solution will lead to better understanding of the properties of materials. However, few studies on regenerated ASF solution have been reported. In this work, we investigated the conformational changes of ASF before and after regenerated process through $\mathrm{x}$-ray diffraction (XRD) analysis. The influence of dissolution on molecule weight was studied with rheological method as well. Furthermore, we prepared regenerated A. pernyi silk fibroin film with good mechanical property which has potential applications in biomedical fields.

\section{EXPERIMENTAL DETAILS}

Native silk fibroin was collected from the silk gland of A. pernyi silkworm. The gel-like silk fibroin was immersed in deionized water for several times in order to remove silk sericin as much as possible after peeling the epithelial skin of the gland by forceps. A. pernyi silk cocoon was degummed with 0.5 wt. $\% \mathrm{Na}_{2} \mathrm{CO}_{3}$ aqueous solution for $30 \mathrm{~min}$ at $100^{\circ} \mathrm{C}$ twice and then dried in vacuum drier at $50{ }^{\circ} \mathrm{C} .340 \mathrm{~g} \mathrm{Ca}\left(\mathrm{NO}_{3}\right)_{2} \cdot 4 \mathrm{H}_{2} \mathrm{O}$ was melted at $100{ }^{\circ} \mathrm{C}$ to turn to the aqueous solution of $\mathrm{Ca}\left(\mathrm{NO}_{3}\right)_{2}$ and then $10 \mathrm{~g}$ degummed silk fibers were dissolved in. After being filtered, the fibroin solution was dialyzed against deionized water for 3 days at $4{ }^{\circ} \mathrm{C}$ with a $12-14 \mathrm{kDa}$ cutoff semipermeable membrane to remove the salt.

Both native gel-like silk fibroin and RASF solution were frozen at $-20{ }^{\circ} \mathrm{C}$ for $24 \mathrm{~h}$ and then lyophilized in freeze dryer. The samples were kept in vacuum drier for further experiments.

To concentrate the aqueous solution of RASF till $10 \mathrm{wt} . \%$, the original one (around $4 \mathrm{wt} . \%$ ) was filled into a $12-14 \mathrm{kDa}$ cutoff semipermeable membrane and then immersed in PEG 20000 solution at $4{ }^{\circ} \mathrm{C}$. RASF films were obtained by casting such a solution on polystyrene 
substrate at $20^{\circ} \mathrm{C}$ and dried for 1 day. B. mori cocoons were degummed with $\mathrm{NaHCO}_{3}$ aqueous solution and then dissolved in $\mathrm{LiBr}$ aqueous solution. RBSF films were obtained as the same method mentioned above, according to the established procedures [24].

X-ray diffraction curves were recorded with a Bruker D8 ADVANCE and DAVINCI.DESIGN X-ray powder diffractometer, with $40 \mathrm{kV}$ voltage and $40 \mathrm{~mA}$ current of the X-ray source, respectively [25].

The thermal stability of sample was examined up to $500{ }^{\circ} \mathrm{C}$ through Perkin Elmer Pyris-1 thermogravimetric analyzer (TGA) at a heating rate of $10{ }^{\circ} \mathrm{C} / \mathrm{min}$. A purging nitrogen gas stream of $40 \mathrm{~mL} / \mathrm{min}$ was used.

The lyophilized native and regenerated ASF were dissolved in ion liquid of AmimCl (1-allyl-3methylimidazolium chloride) for rheological measurements, which were carried on a stress-controlled rheometer, Physical MCR-301 (Anton Paar Co. Inc.), protected with $\mathrm{N}_{2}$ through a H-PTD200 hood with peltier heating/cooling system, according to the established procedures [26].The storage and loss modulus, $G^{\prime}(\omega)$ and $G^{\prime \prime}(\omega)$, were measured as functions of frequency $\omega$ for the native and regenerated $\mathrm{ASF} / \mathrm{AmimCl}$ solutions.

Tensile tests were carried out on Instron 5565 universal test machine at room temperature and $50 \pm 5 \%$ RH.

\section{RESULTS AND DISCUSSION}

\subsection{X-Ray diffraction curves}

Fig. 1 showed the XRD curves of native ASF, RASF film and RASF film after methanol treatment. In native and regenerated ASF samples, the $2 \theta$ pattern was characterized by the presence of $11.5^{\circ}$ and $22.5^{\circ}$, which was characteristic of $\alpha$-helix crystalline structure [27]. It could be concluded that these two samples contained a variable proportion of $\alpha$-helix due to the presence of $($ Ala $)$ - repeats in the primary structure of the protein, as well as random coil conformation. After treatment by immersing in $80 \%$ (v/v) methanol-water solution for $24 \mathrm{~h}$, the re-dried RASF film exhibited rather different diffraction curve, with a major peak at about $20.5^{\circ}$, and two minor peaks, in shoulder form, at $16.5^{\circ}$ and $24.5^{\circ}$. The crystalline spacings were features of $A$. pernyi film with $\beta$ sheet structure. The reason for conformation transition of silk fibroin from $\alpha$-helix to $\beta$-sheet should lie on methanol could destroy inter- or intra molecular hydrogen bonds to induce the movement of protein chain and the dehydration of methanol-water solution also contributed to the formation of insoluble $\beta$-sheet structure [27].

Besides, both lyophilized ASF sample and RASF film could be dissolved in water easily. Combining the result from XRD, we concluded that the dissolution with $\mathrm{Ca}\left(\mathrm{NO}_{3}\right)_{2}$ did not affect the conformation of ASFs, as they were primarily composed of $\alpha$-helix and random coli conformation.

\subsection{Thermal properties}

Fig. 2 displayed the differential thermogravimetric curves of native ASF, RASF and RBSF samples. At the first peak between 60 and $120{ }^{\circ} \mathrm{C}$ in DTG curves, the weight loss was obviously due to water vaporization. As temperature increased to $500{ }^{\circ} \mathrm{C}$, the thermal effect of both ASF samples presented three main steps: (i) small peak at $225^{\circ} \mathrm{C}$, slight thermal decomposition of silk fibroin molecules (ii) shoulder at $250-370^{\circ} \mathrm{C}$, a sharp drop of weight loss and (iii) peak at $370-420^{\circ} \mathrm{C}$, a main degradation.

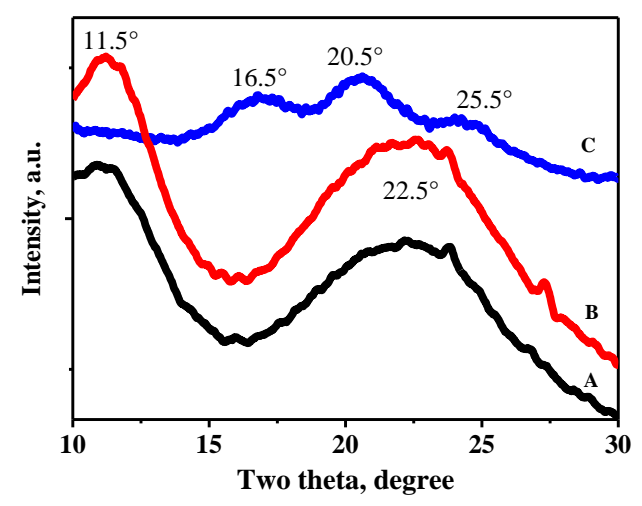

Fig. 1. X-ray diffraction patterns of native ASF (A), RASF film (B) and RASF film-methanol treatment (C)

On the other side, thermal decomposition of RBSF film which took place in a single step and the maximum thermal degradation rate occurred at around $295^{\circ} \mathrm{C}$ was totally different. Reasonably, it was due to different amino acid compositions as well as conformations involved in ASF and BSF. Moreover, there was essentially no difference in thermal behaviors between native and regenerated ASF sample, which was in agreement with the XRD observation.

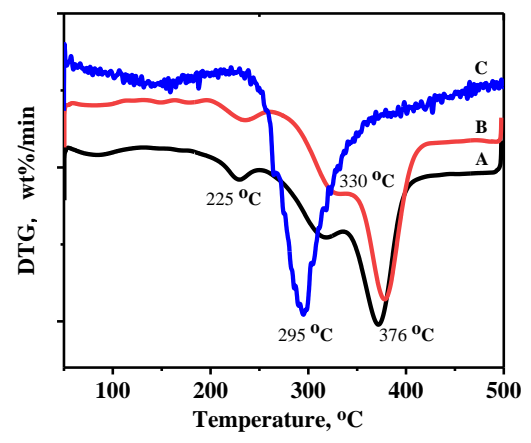

Fig. 2. DTG spectra of native ASF (A), RASF film (B) and RBSF film (C)

\subsection{Molecule weight of $A$. pernyi silk fibroin}

It is well known that the molecule weight of polymer has a great effect on properties of materials. In regenerated process, multiple factors including the solvent and temperature, etc. would contribute to the degradation of silk fibroin. Therefore, we estimated the molecule weight of native and regenerated ASF samples to find out whether the $\mathrm{Ca}\left(\mathrm{NO}_{3}\right)_{2}$ solution was suitable for preparing RASF.

Silk fibroin, which has the amphiphilic structure of molecular chain, tends to aggregate in aqueous solution, and the degradation of SF is thought to be random. Therefore many traditional measurements of molecule weight are not suitable for the regenerated silk fibroin 
[28-30]. Wang [26] et al. invented a rheological method based on ionic liquid solution to calculate molecule weight of RBSF. In general, the linear viscoelastic moduli of RBSF/AmimCl solution exhibited Rouse-like behavior, which described the relationship between modulus, concentration and molecule weight. By fitting the experimental modulus data with the Rouse model (Eq. 1 - Eq. 3), molecule weight could be calculated.

$$
\begin{aligned}
& G^{\prime}=\sum_{i}\left[f(i)\left(\rho R T / M_{i}\right) \sum_{p=1}^{N} \frac{\omega^{2} \tau_{i p}^{2}}{1+\omega^{2} \tau_{i p}^{2}}\right] ; \\
& G^{\prime \prime}=\sum_{i}\left[f(i)\left(\rho R T / M_{i}\right) \sum_{p=1}^{N} \frac{\omega \tau_{i p}}{1+\omega^{2} \tau_{i p}^{2}}\right] ; \\
& \tau_{i p}=6 \eta_{0} M_{i} /\left(\pi^{2} p^{2} R T\right),
\end{aligned}
$$

where $\rho$ is the density, $R$ is the gas constant and $T$ is the absolute temperature, $\eta_{0}$ is the zero-shear viscosity, $M i$ and $f(i)$ are the molecular weight and weight fraction of the $i$-th component, $\tau_{i \mathrm{p}}$ is the relaxation time of the $i$-th component, respectively.

The chemical structure and composition of ASF was obviously different from those of BSF, which was demonstrated by DTG observation mentioned above. Firstly, we checked if the method was suitable for ASF.

According to the result of gene sequencing, the amino acid sequence of ASF contains 2,639 amino acid residues, producing a molecule weight of $216 \mathrm{kDa}[12,31]$. We carried the experiments at $30{ }^{\circ} \mathrm{C}, 20^{\circ} \mathrm{C}$ and $10{ }^{\circ} \mathrm{C}$ (Fig. 3 and Fig. 4).

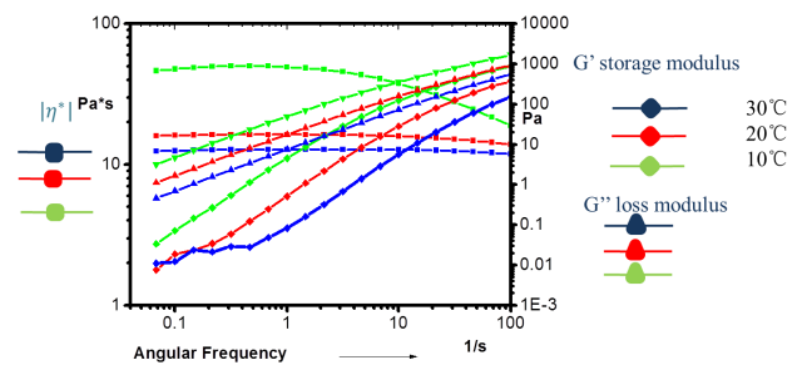

Fig. 3. Viscosity, $G^{\prime}(\omega)$ and $G^{\prime \prime}(\omega)$ for the native A.pernyi silk fibroin solution at different temperature

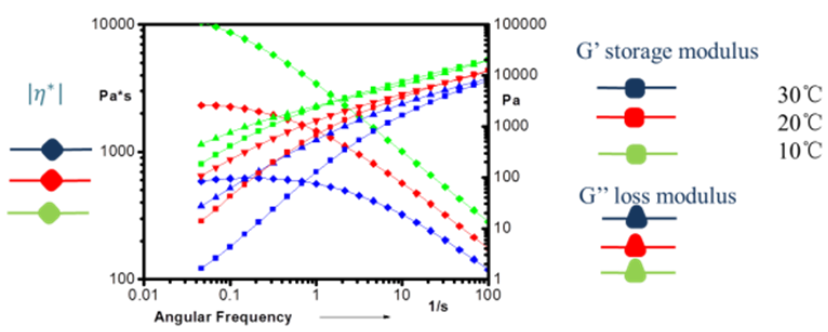

Fig. 4. Viscosity, $G^{\prime}(\omega)$ and $G^{\prime \prime}(\omega)$ for the regenerated A.pernyi silk fibroin solution at different temperature

After fitting, we compared the storage and loss modulus (scatter) for the native ASF/AmimCl solution and theoretical curves (line) based on Rouse-model with the Gaussian distribution, as shown in Fig. 5 a. The result showed that the weight-average molecular weight $\left(\mathrm{M}_{\mathrm{w}}\right)$ for the native ASF was $246 \mathrm{kDa}$, which was only a little higher than $216 \mathrm{kDa}$, suggesting this method for determining molecular weight of ASF was reliable. Besides, as the number-average molecular weight $\left(M_{n}\right)$ was $242 \mathrm{kDa}$, the polydispersity index $\left(\mathrm{M}_{\mathrm{w}} / \mathrm{M}_{\mathrm{n}}\right)$ of the molecular weight of the native ASF was calculated to 1.01, which was consistent with the fact of biosynthesized protein. In such a situation, $M_{w}$ and $M_{n}$ for RASF were estimated to $199 \mathrm{kDa}$ and $96 \mathrm{kDa}$, respectively, according to the fitting in Fig. 5 b. These results suggested that the $\mathrm{Ca}\left(\mathrm{NO}_{3}\right)_{2}$ dissolution process damaged molecule chain of ASF to an acceptable degree, and the degradation of the ASF was truly random (Fig. 6).

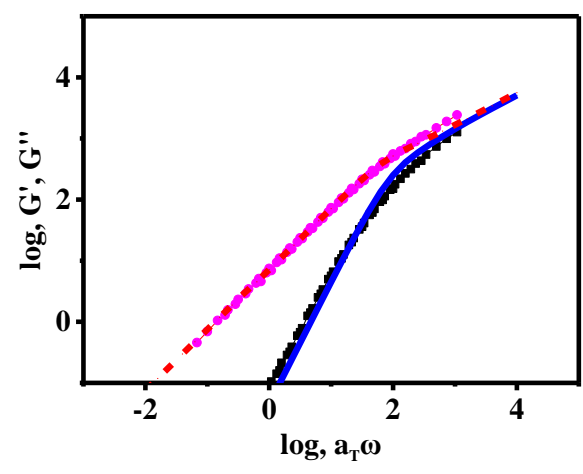

a

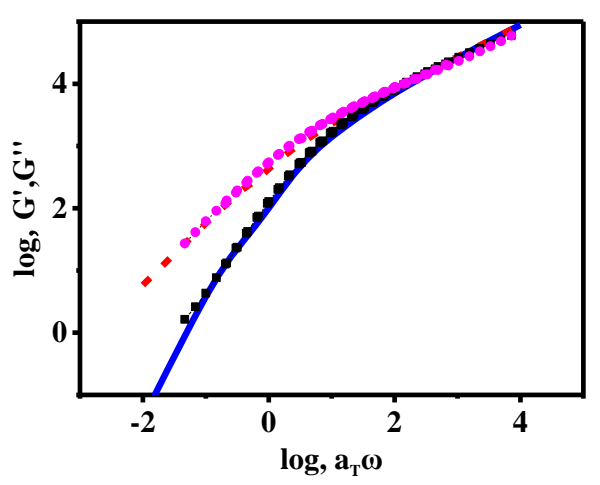

b

Fig. 5. $a$-native ASF; b-regenerated ASF samples: Linear storage and loss modulus, $G$ ' (dashed) and $G^{\prime}$ (solid). The lines are the theoretical curves based on the Rouse model incorporating with Gaussian distribution of molecular weight

\subsection{Mechanical properties}

With good transmission and biocompatibility, RASF film has attracted researchers' attention. For examples, Li et al studied structure change in RASF film induced by ethanol [32], and Kweon et al worked out the conformational change in RASF film with heat treatment[33]. However, the RASF trended to aggregate in aqueous solution during the concentrated process, these investigation were based on low concentration solution $(<3$ wt.\%) and thin film, which could only be used for structure study rather than the mechanical test.

In our work, we harvested the RASF aqueous solution with high concentration (about $10 \mathrm{wt} . \%$ ) via the low temperature reversing dialysis in PEG solution. Then the 
round-shape RASF film with a size of $70 \mathrm{~mm}$ in diameter and $100 \mu \mathrm{m}$ in thickness was cast. The stress-strain curve of the RASF film was shown in Fig. 7, displaying a typical brittle fracture. The average breaking stress and breaking strain of RASF film were $60.4 \mathrm{MPa}$ and $2.5 \%$, respectively, which was higher than existing reports [34].

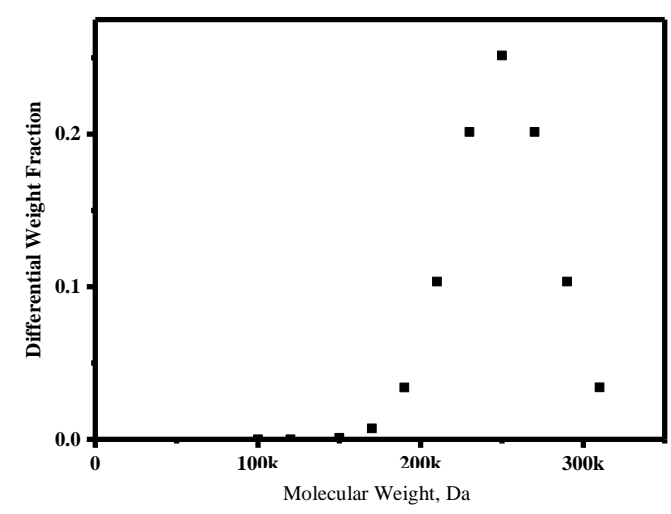

a

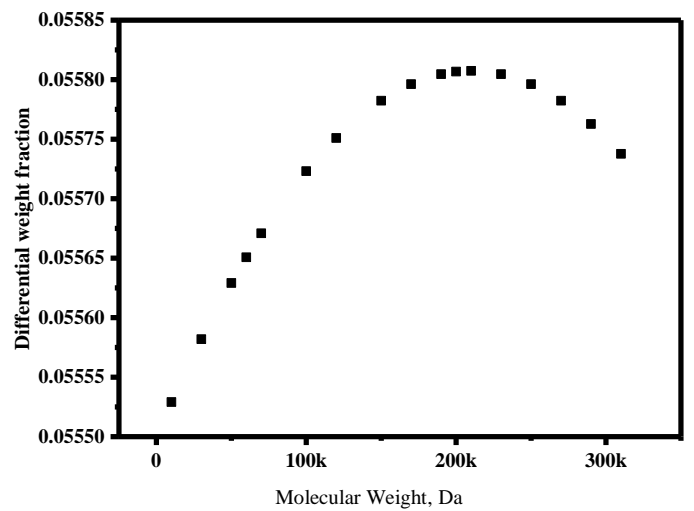

b

Fig. 6. $a$-native ASF; b-regenerated ASF: Molecular weight distribution obtained from fitting viscoelastic moduli with the Rouse model

The stress-strain curves of $A$. pernyi and B. mori silk fibers were shown in Fig. 7 insert.

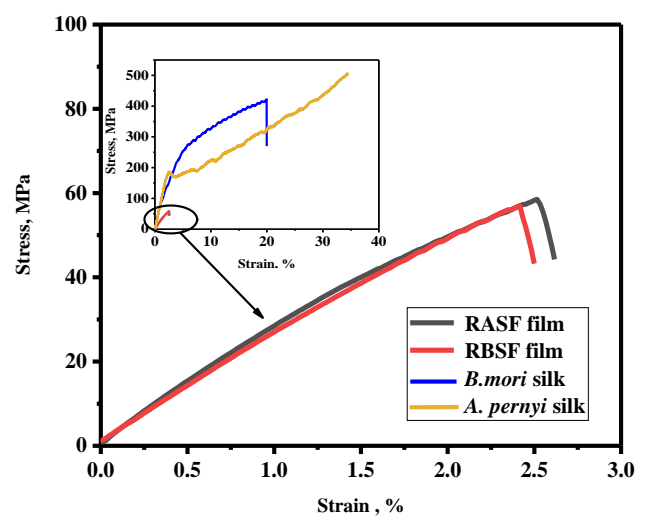

Fig. 7. Stress-strain curves of RASF film and RBSF film (Insert: stress-strain curves of RASF film, RBSF film, A. pernyi silk fiber and $B$. mori silk fiber)
Remarkably, the mechanical properties of natural fibers were infinitely superior to those of regenerated films. This could be attributed to the fact that the final properties were greatly affected by the structure. The natural silk fiber could be regarded as a semi-crystalline material, within which macromolecular chains as well as the nano-fibrils were oriented parallel to the fiber axis, producing during the spinning process of silkworm. It was widely accepted that highly ordered/oriented regions mainly define the strength and stiffness, while amorphous regions contribute to the elasticity of silks $[35,36]$. On the other sides, the molecule chains were poorly aligned in the regenerated silk fibroin film, combining with some of entanglements [37]. Such a structure caused insufficient intermolecular interaction to induce the sliding between silk fibroin chain at low tensile stress/strain [38]. In all, it suggested that the varied structures among natural silk fibers and regenerated silk fibroin based materials rather than other factors such as molecular weight etc. determined the differences of their mechanical properties.

Furthermore, the stress-strain curves of A. pernyi silk fiber might had a distinct yield point followed by obvious strain hardening. In contrast, B. mori silk fiber displayed an unapparent distinct yield point and mild strain hardening. In $B$. mori silk, the main repeating motif GAGAGS formed the $\beta$-sheets, with Gly facing one side and Ala the other side [39]. However, the crystal structure of $A$. pernyi silk was found to be the combination of $\beta$ sheet and $\alpha$-helix composed of short and long polyalanine [40]. Although they shared the similar condensed structure, i.e. oriented chains/nano-fibrils, the variation on the mechanical behaviors of two natural silk fibers were mainly due to their different primary and secondary structures of silk fibroin. However, the fracture behaviors of RASF and RBSF film were nearly identical, despite the differences in their own fibers. The regenerated process, followed with harsh solvents and often high temperatures, totally destroyed original structure of fibers. Therefore, the similar film formation process resulted in the same mechanical properties of silk fibroin.

\section{CONCLUSIONS}

In summary, in regenerated $A$. pernyi silk fibroin solution obtained by dissolving degummed fibers with melted $\mathrm{Ca}\left(\mathrm{NO}_{3}\right)_{2} \cdot 4 \mathrm{H}_{2} \mathrm{O}$, the conformations of RASF were similar to those of native ASF, mainly contained $\alpha$-helix and random coil structure. Mw for RASF was $199 \mathrm{kDa}$, which was about $80 \%$ of that of native ASF. Although other research evidenced that the mechanical characters of RASF scaffold which were obtained with such RASF/1butanol solution under freezing process were quite different from the counterparts of RBSF [16], the mechanical properties of our as-prepared RASF film were the same as the one of RBSF film. The RASF film was characterized by a breaking stress reaching $60.4 \mathrm{MPa}$, which had potential in tendon and ligament regeneration [41]. In all, our research may help in improvement and modification to produce wild silk-based materials for specific applications. 


\section{Acknowledgments}

This work was supported by the Natural Science Foundations of China (NSFC 21574024).

\section{REFERENCES}

1. Kundu, S., Kundu, B., Talukdar, S., Bano, S., Nayak, S., Kundu, J., Mandal, B.B., Bhardwaj, N., Botlagunta, M., Dash, B.C. Nonmulberry Silk Biopolymers Biopolymers 97 2012: pp. $455-467$. https://doi.org/10.1002/bip.22024

2. Suzuki, Y., Kawanishi, S., Yamazaki, T., Aoki, A., Saito, H., Asakura, T. Structural Determination of the Tandem Repeat Motif in Samia Cynthia Ricini Liquid Silk by Solution NMR Macromolecules 48 2015: pp. $6574-6579$. https://doi.org/10.1021/acs.macromol.5b01717

3. Kawahara, Y. Influence of Pigments on Graft Polymerization of Methacrylamide onto Wild Silk Fibers Journal of Macromolecular Science: Part A-Chemistry 33 1996: pp. $359-363$.

https://doi.org/10.1080/10601329608019156

4. Vepari, C., Kaplan, D.L. Silk as a Biomaterial Progress in Polymer Science 32 2007: pp. 991-1007.

https://doi.org/10.1016/j.progpolymsci.2007.05.013

5. Rockwood, D.N., Preda, R.C., Yücel, T., Wang, X., Lovett, M.L., Kaplan, D.L. Materials Fabrication from Bombyx mori Silk Fibroin Nature Protocols 6 2011: pp. $1612-1631$. https://doi.org/10.1038/nprot.2011.379

6. Tao, H., Kaplan, D.L., Omenetto, F.G. Silk Materials-A Road to Sustainable High Technology Advanced Materials 24 2012: pp. 2824-2837.

https://doi.org/10.1002/adma.201104477

7. Altman, G.H., Diaz, F., Jakuba, C., Calabro, T., Horan, R.L., $\quad$ Chen, J., $\quad$ Lu, H., $\quad$ Richmond, J., Kaplan, D.L. Silk-based Biomaterials Biomaterials 24 2003: pp. $401-416$.

https://doi.org/10.1016/S0142-9612(02)00353-8

8. Cao, Z., Wen, J., Yao, J., Chen, X., Ni, Y., Shao, Z. Facile Fabrication of the Porous Three-dimensional Regenerated Silk Fibroin Scaffolds Materials Science and Engineering: C 33 2013: pp. 3522-3529.

https://doi.org/10.1016/j.msec.2013.04.045

9. Chen, M., Shao, Z., Chen, X. Paclitaxel-loaded Silk Fibroin Nanospheres Journal of Biomedical Materials Research Part A 100 2012: pp. 203-210.

https://doi.org/10.1002/jbm.a.33265

10. Srisuwan, Y., Srihanam, P., Baimark, Y. Preparation of Silk Fibroin Microspheres and Its Application to Protein Adsorption Journal of Macromolecular Science: Part A Chemistry 46 2009: pp. 521-525. https://doi.org/10.1080/10601320902797780

11. Expasy, Expert Protein Analysis System. P05790-P07856.

12. Expasy, Expert Protein Analysis System. O76786.

13. Tsukada, M., Freddi, G., Gotoh, Y., Kasai, N. Physical and Chemical Properties of Tussah Silk Fibroin Films Journal of Polymer Science Part B: Polymer Physics 32 1994: pp. $1407-1412$. https://doi.org/10.1002/polb.1994.090320812

14. Zhu, Z., Ohgo, K., Watanabe, R., Takezawa, T., Asakura, T. Preparation and Characterization of Regenerated Bombyx mori Silk Fibroin Fiber Containing Recombinant Cell-Adhesive Proteins; Nonwoven Fiber and
Monofilament Journal of Applied Polymer Science 109 2008: pp. 2956-2963. https://doi.org/10.1002/app.28460

15. Li, M., Tao, W., Lu, S., Zhao, C. Porous 3-D Scaffolds from Regenerated Antheraea pernyi Silk Fibroin Polymers for Advanced Technologies 19 2008: pp. 207-212. https://doi.org/10.1002/pat.998

16. Duan, Y., Chen, X., Shao, Z.Z. Preparation and Properties of Antheraea pernyi/Bombyx mori Silk Fibroin Blending Scaffold Acta Chimica Sinica 76 2018: pp. 190-195. https://doi.org/10.6023/A17110511

17. Tsukada, M. Structural Changes Induced in Tussah Silk (Antheraea pernyi) Fibroin Films by Immersion in Methanol Journal of Polymer Science Part B: Polymer Physics 24 1986: pp. $1227-1232$. https://doi.org/10.1002/polb.1986.090240603

18. Tsukada, M., Freddi, G., Kasai, N., Monti, P. Structure and Molecular Conformation of Tussah Silk Fibroin Films Treated with Water-methanol Solutions: Dynamic Mechanical and Thermomechanical Behavior Journal of Polymer Science Part B: Polymer Physics 36 1998: pp. 2717-2724.

https://doi.org/10.1002/(SICI)10990488(19981115)36:15<2717::AID-POLB5>3.3.CO;2-F

19. Nakazawa, Y., Asakura, T. High-resolution C-13 CP/MAS NMR Study on Structure and Structural Transition of Antheraea pernyi Silk Fibroin Containing Poly(L-alanine) and Gly-rich Regions Macromolecules 35 2002: pp. 2393-2400. https://doi.org/10.1021/ma011999t

20. Zuo, B., Liu, L., Zhang, F. Structure and Properties of Regenerated Antheraea pernyi Silk Fibroin Filaments Journal of Applied Polymer Science 113 2009: pp. $2160-2165$. https://doi.org/10.1002/app.30347

21. Kweon, H., Park, Y.H. Dissolution and Characterization of Regenerated Antheraea pernyi Silk Fibroin Journal of Applied Polymer Science 82 2001: pp. 750-758. https://doi.org/10.1002/app.1901

22. Yamada, H., $\quad$ Nakao, H.Y., $\quad$ Takasu Tsubouchi, K. Preparation of Undegraded Native Molecular Fibroin Solution from Silkworm Cocoons Materials Science and Engineering: $C 14$ 2001: pp. 41-46. https://doi.org/10.1016/S0928-4931(01)00207-7

23. Cao, H., Chen, X., Huang, L., Shao, Z. Electrospinning of Reconstituted Silk Fiber from Aqueous Silk Fibroin Solution Materials Science and Engineering: C 29 2009: pp. 2270-2274. https://doi.org/10.1016/j.msec.2009.05.012

24. Luo, K.Y., Yang, Y.H., Shao, Z.Z. Physically Crosslinked Biocompatible Silk-Fibroin-Based Hydrogels with High Mechanical Performance Advanced Functional Materials 26 2016: pp. 872-880. https://doi.org/10.1002/adfm.201503450

25. Yuan, Q.Q., Yao, J.R., Chen, X., Huang, L., Shao, Z.Z. The Preparation of High Performance Silk Fiber/Fibroin Composite Polymer 51 2010: pp. 4843-4849. https://doi.org/10.1016/j.polymer.2010.08.042

26. Wang, Q. Chen, Q., Yang, Y., Shao, Z. Effect of Various Dissolution Systems on the Molecular Weight of Regenerated Silk Fibroin Biomacromolecules 14 2012: pp. $285-289$. https://doi.org/10.1021/bm301741q

27. Tsukada, M., Freddi, G., Monti, P., Bertoluzza, A., Kasai, N. Structure and Molecular-conformation of Tussah 
Silk Fibroin Films-Effect of Methanol Journal of Polymer Science Part B-Polymer Physics 33 1995: pp. $1995-2001$.

https://doi.org/10.1002/polb.1995.090331402

28. Cho, H.J., Ki, C.S., Oh, H., Lee, K.H., Um, I.C. Molecular Weight Distribution and Solution Properties of Silk Fibroins with Different Dissolution Conditions International Journal of Biological Macromolecules 51 2012: pp. 336-341. https://doi.org/10.1016/j.ijbiomac.2012.06.007

29. Horan, R.L., Antle, K., Collette, A.L., Wang, Y., Huang, J., Moreau, J.E., Volloch, V., Kaplan, D.L., Altman, G.H. In vitro Degradation of Silk Fibroin Biomaterials 26 2005: pp. 3385-3393. https://doi.org/10.1016/j.biomaterials.2004.09.020

30. Greving, I., Dicko, C., Terry, A., Callow, P., Vollrath, F. Small Angle Neutron Scattering of Native and Reconstituted Silk Fibroin Soft Matter 6 2010: pp. 4389-4395. https://doi.org/10.1039/c0sm00108b

31. Sezutsu, H., Yukuhiro, K. Dynamic Rearrangement within the Antheraea pernyi Silk Fibroin Gene is Associated with Four Types of Repetitive Units Journal of Molecular Evolution 51 2000: pp. 329-338. https://doi.org/10.1007/s002390010095

32. Li, M., Tao, W., Kuga, S., Nishiyama, Y. Controlling Molecular Conformation of Regenerated Wild Silk Fibroin by Aqueous Ethanol Treatment Polymers for Advanced Technologies 14 2003: pp. 694-698. https://doi.org/10.1002/pat.409

33. Kweon, H., Woo, S.O., Park, Y.H. Effect of Heat Treatment on the Structural and Conformational Changes of Regenerated Antheraea Pernyi Silk Fibroin Films Journal of Applied Polymer Science 81 2001: pp. 2271-2276. https://doi.org/10.1002/app.1667.abs

34. Lu, S.Z., Mao, L., Liu, Y., Sun, S., Li, G.J. Preparation of Water-Insoluble Antheraea Pernyi Silk Fibroin Films Advanced Materials Research 569 2012: pp. 311-315.
https://doi.org/10.4028/www.scientific.net/AMR.569.311

35. Termonia, Y. Molecular Modeling of Spider Silk Elasticity Macromolecules 27 1994: pp. 7378-7381.

https://doi.org/10.1021/ma00103a018

36. Porter, D., Vollrath, F., Shao, Z. Predicting the Mechanical Properties of Spider Silk as A Model Nanostructured Polymer The European Physical Journal E 16 2005: pp. $199-206$. https://doi.org/10.1140/epje/e2005-00021-2

37. Chen, X., Knight, D.P., Shao, Z.Z., Vollrath, F. Conformation Transition in Silk Protein Films Monitored by Time-resolved Fourier Transform Infrared Spectroscopy: Effect of Potassium Ions on Nephila spidroin Films Biochemistry 41 2002: pp. 14944-14950. https://doi.org/10.1021/bi026550m

38. Yin, J., Chen, E., Porter, D., Shao, Z. Enhancing the Toughness of Regenerated Silk Fibroin Film through Uniaxial Extension Biomacromolecules 2010: pp. $2890-2895$. https://doi.org/10.1021/bm100643q

39. Drummy, L.F., Farmer, B.L., Naik, R.R. Correlation of the [Small Beta]-sheet Crystal Size in Silk Fibers with the Protein Amino Acid Sequence Soft Matter 3 2007: pp. $877-882$. https://doi.org/10.1039/b701220a

40. Tsukada, M., Freddi, G., Nagura, M., Ishikawa, H., Kasai, N. Structural-changes of Silk Fibers Induced by Heattreatment Journal of Applied Polymer Science 46 1992: pp. $1945-1953$. https://doi.org/10.1002/app.1992.070461107

41. Jao, D., Mou, X.Y., Hu, X. Tissue Regeneration: A Silk Road Journal of Functional Biomaterials 7 (3) 2016: pp. 22.

https://doi.org/10.3390/jfb7030022

(C) Duan et al. 2021 Open Access This article is distributed under the terms of the Creative Commons Attribution 4.0 International License (http://creativecommons.org/licenses/by/4.0/), which permits unrestricted use, distribution, and reproduction in any medium, provided you give appropriate credit to the original author(s) and the source, provide a link to the Creative Commons license, and indicate if changes were made. 